\title{
Development of Two Cancers in the Same Patient after Ileorectal and Ileal Pouch Anal Anastomosis for Familial Adenomatous Polyposis
}

\author{
Murat Ulaş ${ }^{a}$ Gürel Neşşar ${ }^{a}$ Akın Bostanoğlu ${ }^{a}$ Gülden Aydoğ ${ }^{b}$ \\ Cüneyt Kayaalp ${ }^{a}$ Yusuf Özoğul $^{a}$ Canbek Seven $^{a}$ \\ Departments of a Gastrointestinal Surgery, and ${ }^{b}$ Pathology, Yüksek İhtisas Hospital, Ankara, Turkey
}

\section{Key Words}

Familial adenomatous polyposis $\cdot$ lleorectal anastomosis $\cdot$ lleal pouch anal anastomosis $\cdot$ Cancer

\begin{abstract}
Objective: To report a case of a patient with familial adenomatous polyposis. Clinical Presentation and Intervention: A 36-year-old male patient who suffered from rectal bleeding was treated with colectomy and ileorectal anastomosis for familial adenomatous polyposis (FAP) in 1974. After 19 years, in situ adenocarcinoma was detected in the rectal stump. Completion proctectomy, mucosectomy, and hand-sewn ileal pouch anal anastomosis with protective ileostomy were performed. In 2002, a metachronous cancer was detected at the anastomosis and abdominoperineal resection of the pouch and end ileostomy were performed. Later on, the perineum was excised locally because of cancer recurrence. Conclusion: This case shows that lifetime surveillance of the FAP patients after surgery is crucial.
\end{abstract}

\section{KARGER}

Fax +4161306 1234 E-Mail karger@karger.ch www.karger.com

\section{Introduction}

Familial adenomatous polyposis (FAP) is an inherited, autosomal dominant syndrome caused by a germ line mutation of the adenomatous polyposis coli gene. Columnar epithelium cells of the large bowel carry this mutation which may lead to malignant transformation. Therefore, prophylactic surgical treatment is recommended. Colectomy and ileorectal anastomosis (IRA) or proctocolectomy and ileal pouch anal anastomosis (IPAA) are the surgical options for the patients. However, there have been reports of cancer developments after both types of surgery had been performed [1]. To the best of our knowledge, this is the first report of two separate cancers in the same patient after performing IRA and IPAA.

\section{Case Report}

A 36-year-old male patient treated with colectomy and IRA for FAP in 1974 suffered from rectal bleeding after 19 years and rectoscopy revealed a degenerated polyp (in situ adenocarcinoma) in the rectum. Completion proctectomy, mucosectomy and handsewn IPAA with protective ileostomy were performed. The pathology report showed that the tumor was consistent with Duke's A classification. Ileostomy was taken down after 3 months. 
Fig. 1. Mucinous adenocarcinoma invasion beneath the anal canal epithelium. HE. $\times 25$.

Fig. 2. Flat adenoma, showing adenomatous tubular glands with crowded, hyperchromatic nuclei between the nonneoplastic mucosa. HE. $\times 25$.
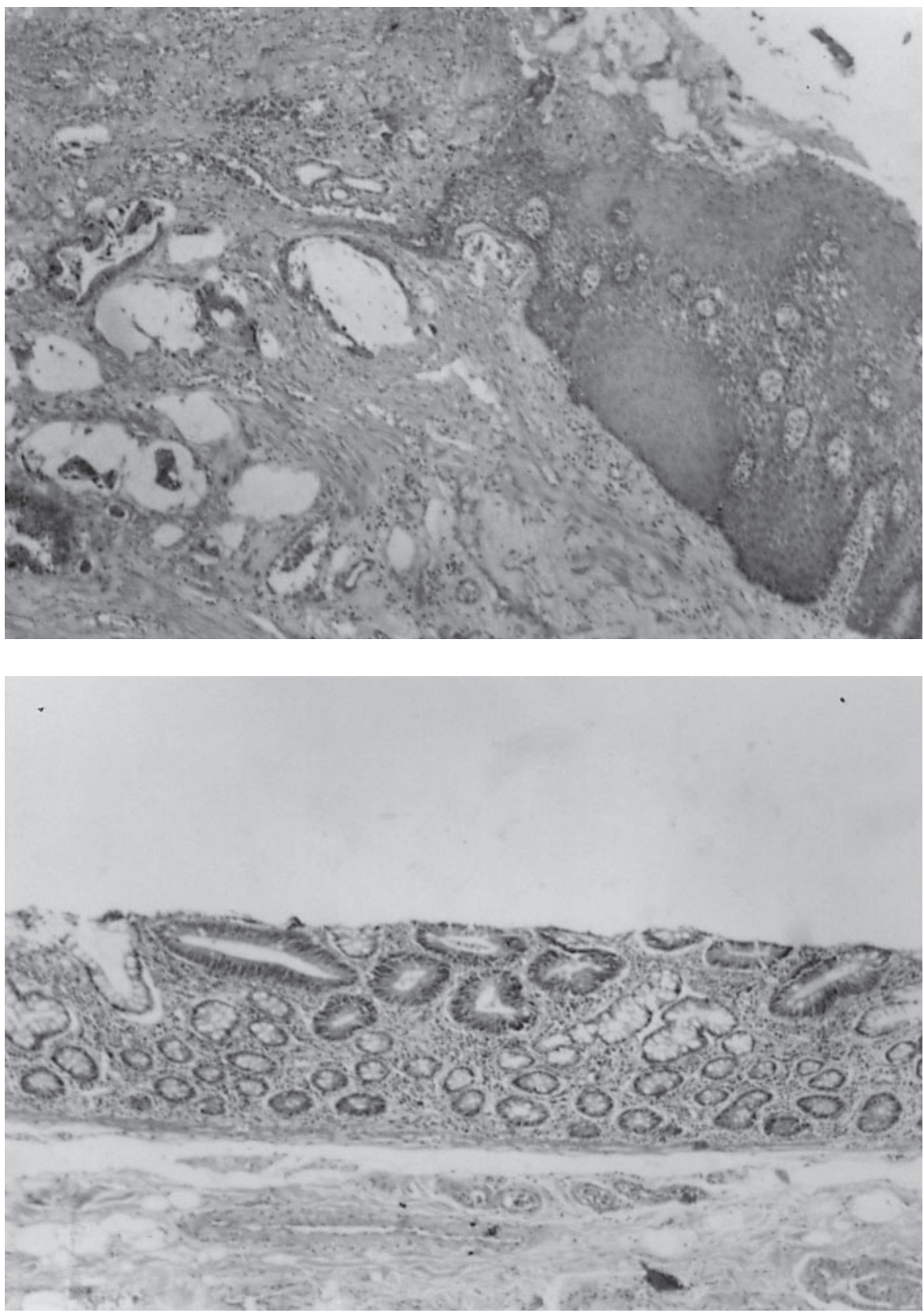

In 2002, 9 years after IPAA operation, the patient had pain, rectal bleeding and difficult defecation. Digital rectal examination showed that the anastomosis was located at $3 \mathrm{~cm}$ from the anal verge. There was a narrowing and a mass at the anastomosis. Rectoscopy revealed irregular appearance and the biopsy showed mucinous adenocarcinoma. There was no distant metastasis. Abdominoperineal resection of the pouch and end ileostomy were performed. Macroscopic and histologic findings of the anastomosis were consistent with mucinous adenocarcinoma. The tumor invaded through the muscularis propria and into nonperitonealized perirectal tissues (fig. 1) with no lymph node metastasis. The tumor was Duke's B stage. Macroscopic examination of the ileal pouch showed that there were slightly elevated lesions. Microscopically, these were consistent with flat adenoma with atypical epithelial tubules (fig. 2). The patient came back again with perineal recurrence in May 2003. There was no distant metastasis and he underwent wide excision of the tumor with peripheral tissues. Histopathological examination revealed an adenocarcinoma located beneath the squamous cells of the perineum (fig. 3). 
Fig. 3. Adenocarcinoma (arrows) beneath the squamous cells of the perineum. HE. $\times 80$.

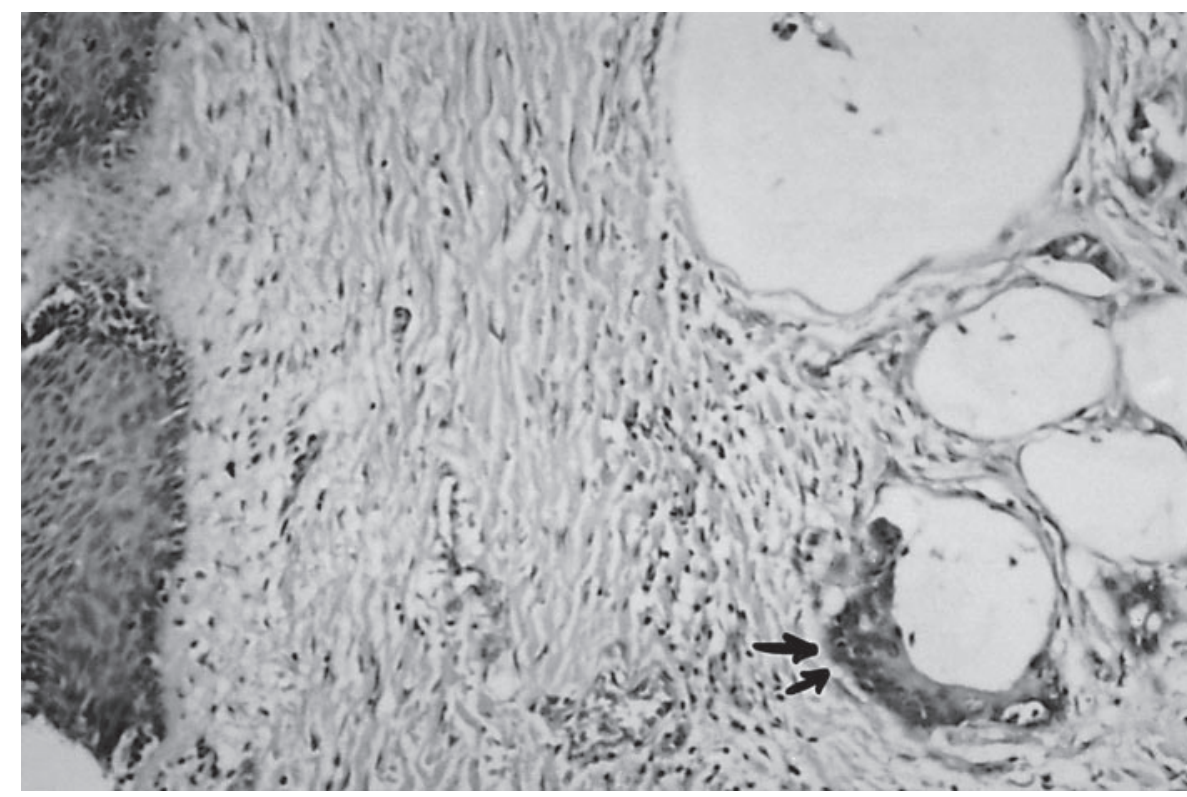

\section{Discussion}

Colectomy and IRA have been used for FAP patients because the technique is a simple procedure with a low complication rate and good functional outcome [2]. The disadvantage of this technique is retained rectum which necessitates repeated endoscopic follow-up. An increased risk of developing rectal cancer in patients treated with IRA has been reported [3]. The risk factors include the length of the postoperative period, the length of the retained rectum, age, and polyp count [3].

In the present case, IRA was performed because IPAA was not an option at that time. The patient had not been followed regularly after the operation. Cancer had developed in the rectum 19 years following surgery and completion proctectomy, mucosectomy, and IPAA which was supposed to eliminate all the risks of cancer. However, another cancer developed at the anastomosis 9 years following IPAA. The long period between the conversion to IPAA and the detection of the second cancer indicates that these are two separate cancers.

The risk of cancer development after IPAA is low theoretically but it may arise from four different regions: ileal pouch, rectal cuff, anal canal, and the mucosa islets which are found after mucosectomy. As shown here, adenomas may be found in the pouch and this is reported in up to $42 \%$ of the cases [4]. The risk of subsequent adenoma developing in the ileal pouch is $75 \%$ at 15 years of follow-up [5]. Three pouch cancer cases have been reported after IPAA to date [6-8].

Retained rectal cuff is a source of malignancy. There have already been three reported cases of cuff cancer in patients with FAP [9-11]. Regarding the anal transitional zone, two cancer cases have been reported [1]. One of them was treated with mucosectomy while the other with a double-stapled technique. Another two anal canal cancer cases after the double-stapled technique have been reported recently [12].

Mucosectomy should be done in patients with polyps going down to the dentate line or in those who have highgrade dysplasia or rectal cancer. In the present study, mucosectomy was performed because of the rectal stump malignancy. There is a substantial risk of polyp formation even if mucosectomy is performed. For this reason, regular surveillance must be rigorous after both types of technique in FAP patients. 


\section{References}

-1 Ooi BS, Remzi FH, Gramlich T, Church JM, Preen M, Fazio VW: Anal transitional zone cancer after restorative proctocolectomy and ileoanal anastomosis in familial adenomatous polyposis: report of two cases. Dis Colon Rectum 2003;46:1418-1423.

-2 Church JM, Fazio VW, Lavery IC, et al: Quality of life after prophylactic colectomy and ileorectal anastomosis in patients with familial adenomatous polyposis. Dis Colon Rectum 1996;39:1404-1408.

$\checkmark 3$ Iwama T, Mishima Y: Factors affecting the risk of rectal cancer following rectum-preserving surgery in patients with familial adenomatous polyposis. Dis Colon Rectum 1994;37:10241026.

-4 Wu JS, McGannon EA, Church JM: Incidence of neoplastic polyps in the ileal pouch of patients with familial adenomatous polyposis after restorative proctocolectomy. Dis Colon Rectum 1998;41:552-557.
5 Parc YR, Olschwang S, Desaint B, Schmitt G, Parc RG, Tiret E: Familial adenomatous polyposis: prevalence of adenomas in the ileal pouch after restorative proctocolectomy. Ann Surg 2001;233:360-364.

6 von Herbay A, Stern J, Herfarth C: Pouch-anal cancer after restorative proctocolectomy for familial adenomatous polyposis. Am J Surg Pathol 1996;20:995-999.

7 Bassauini MM, Billings PJ: Carcinoma in an ileoanal pouch after restorative proctocolectomy for familial adenomatous polyposis. $\mathrm{Br} \mathrm{J}$ Surg 1996;83:506.

-8 Palkar VM, deSouza LJ, Jagannath P, Naresh $\mathrm{KN}$ : Adenocarcinoma arising in ' $\mathrm{J}$ ' pouch after total proctocolectomy for familial polyposis coli. Indian J Cancer 1997;34:16-19.
$>9$ Vuilleumier H, Halkic N, Ksontini R, Gillet M: Columnar cuff cancer after restorative proctocolectomy for familial adenomatous polyposis. Gut 2000;47:732-734.

10 Hoehner JC, Metcalf AM: Development of invasive adenocarcinoma following colectomy with ileoanal anastomosis for familial polyposis coli. Dis Colon Rectum 1994;37:824-828.

11 Brown SR, Donati D, Seow-Choen F: Rectal cancer after mucosectomy for ileoanal pouch in familial adenomatous polyposis: report of a case. Dis Colon Rectum 2001;44:1714-1715.

12 Vrouenraets BC, Van Duijvendijk P, Bemelmen WA, Offerhaus GJ, Slors JF: Adenocarcinoma in the anal canal after ileal pouch-anal anastomosis for familial adenomatous polyposis using a double-stapled technique: report of two cases. Dis Colon Rectum 2004;4:530534. 